\title{
Losartan, an angiotensin-II type I receptor blocker, attenuates the liver fibrosis development of non-alcoholic steatohepatitis in the rat
} Hitoshi Yoshiji*, Ryuichi Noguchi, Yasuhide Ikenaka, Tadashi Namisaki, Mitsuteru Kitade, Kosuke Kaji, Yusaku Shirai, Junichi Yoshii, Koji Yanase, Masaharu Yamazaki, Tatsuhiro Tsujimoto, Hideto Kawaratani, Takemi Akahane, Yosuke Aihara and Hiroshi Fukui

Address: Third Department of Internal Medicine, Nara Medical University, Shijo-cho 840, Kashihara, Nara 634-8522, Japan

Email: Hitoshi Yoshiji* - yoshijih@naramed-u.ac.jp; Ryuichi Noguchi - not available; Yasuhide Ikenaka - not available; Tadashi Namisaki - not available; Mitsuteru Kitade - not available; Kosuke Kaji - not available; Yusaku Shirai - not available; Junichi Yoshii - not available; Koji Yanase - not available; Masaharu Yamazaki - not available; Tatsuhiro Tsujimoto - not available; Hideto Kawaratani - not available; Takemi Akahane - not available; Yosuke Aihara - not available; Hiroshi Fukui - not available

* Corresponding author

Published: 5 May 2009

BMC Research Notes 2009, 2:70 doi:10.1/86/1756-0500-2-70
Received: 10 February 2009

Accepted: 5 May 2009

This article is available from: http://www.biomedcentral.com/I756-0500/2/70

(c) 2009 Yoshiji et al; licensee BioMed Central Ltd.

This is an Open Access article distributed under the terms of the Creative Commons Attribution License (http://creativecommons.org/licenses/by/2.0), which permits unrestricted use, distribution, and reproduction in any medium, provided the original work is properly cited.

\begin{abstract}
Background: Apart from simple steatosis, the non-alcoholic steatohepatitis (NASH) can progress into liver fibrosis and cirrhosis. To date, however, no widely accepted therapeutic modalities have been established against NASH in the clinical practice. To find out promising new therapeutic agents, it is important to employ an appropriate experimental model of NASH, such as association with insulin resistance.

Findings: In the current study, we found that losartan, a clinically used angiotensin-II type I receptor blocker, significantly attenuated a choline-deficient L-amino acid-defined (CDAA) dietinduced steatohepatitis in obese diabetic- and insulin resistance-associated Otsuka Long-Evans Tokushima Fatty (OLETF) rats. The transforming growth factor-beta, a well-known major fibrogenic cytokine, was also suppressed in a similar magnitude to that of the fibrosis area. Noteworthy was the finding that these inhibitory effects were achieved even at a clinically comparable low dose.
\end{abstract}

Conclusion: Since losartan is widely used without serious side effects in the clinical practice, this agent may be an effective new therapeutic strategy against NASH.

\section{Findings}

The spectrum of non-alcoholic fatty liver diseases (NAFLD) ranges from simple steatosis to cirrhosis. Whereas simple steatosis seems to be a benign and nonprogressive condition, non-alcoholic steatohepatitis (NASH) is recognized as a potentially progressive disease that may cause cirrhosis, an end-stage liver disease, and hepatocellular carcinoma (HCC) [1,2]. The patients with NAFLD frequently have many clinical complications, such as obesity, type 2 diabetes mellitus, and insulin resistance [3]. While sustained weight loss should be very effective to improve NAFLD, it is somewhat difficult for many patients to change their life style. Accordingly, efforts are currently directed worldwide at overcoming NAFLD, espe- 
cially NASH. Since insulin resistance is nearly universal in the patients with NASH, and it plays a pivotal role in the pathogenesis of NASH, many studies attempted to employ insulin sensitizer as a therapeutic modality against NASH. Although pioglitazone, a selective peroxisome proliferator-activated receptor gamma agonist, has shown some beneficial effects in the patients with NASH [3], there are still several unsolved questions. Since a longterm treatment is required to maintain the therapeutic benefits, the long-term safety of these drugs in the patients with chronic liver diseases should be proven. Another member of thiazolidinedione (TZD) class; namely, triglitazone caused fulminant hepatitis in several patients. Moreover, recent studies have questioned the long-term safety of TZD, especially rosiglitazone. Furthermore, it has been reported that TZD alone without lifestyle alternation may not achieve the anticipated clinical benefit [4]. Collectively, some time may be still required until the common application of TZD, including pioglitazone, for the treatment of NASH in the clinical practice.

The renin-angiotensin system (RAS) reportedly plays an important role in insulin resistance, and suppression of angiotensin-II (AT-II) ameliorates insulin resistance [5]. We and other group have shown that suppression of AT-II by the clinically used angiotensin-converting enzyme inhibitor (ACE-I) and AT-II type 1 receptor blocker (ARB) significantly attenuated the liver fibrosis development along with inhibition of the activated hepatic stellate cells (HSC) [6]. A choline-deficient, amino acid-defined (CDAA) diet induces histological changes similar to those of the human NASH. It has been reported that ACE-I and ARB markedly attenuated the CDAA-induced liver fibrosis development along with suppression of the activated HSC $[7,8]$. However, a downside of the CDAA model is that it does not exhibit several common features of NASH, such as insulin resistance and diabetes mellitus. To examine the precise pharmacological action of any drug, it is important to examine its therapeutic effect under the condition of insulin resistance. In the current study, we found that losartan, an ARB, significantly suppressed the CDAAinduced liver fibrosis development in the Otsuka LongEvans Tokushima fatty (OLETF) rats, which commonly have obesity, diabetes mellitus, and insulin resistance (Fig. 1). The total experimental period was 12 weeks. The rats received losartan daily in the drinking water $(30 \mathrm{mg} /$ $\mathrm{kg} /$ day) for 8 weeks from week 4 . The concentration of losartan in the drinking water was adjusted according to the water intake to maintain a constant daily dose of the drug. This dose was almost comparable to that used in the clinical practice as described previously [9]. Losartan treatment did not cause alterantion of the serum ALT level, indicating that the losartan did not cause hepatotoxicity, and the inhibitory effect of losartan was not a secondary response to a cytoprotection effect of this agent against
A
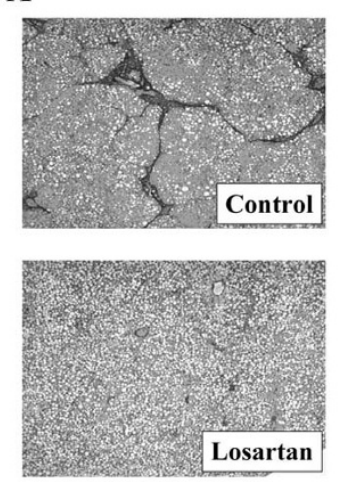

B

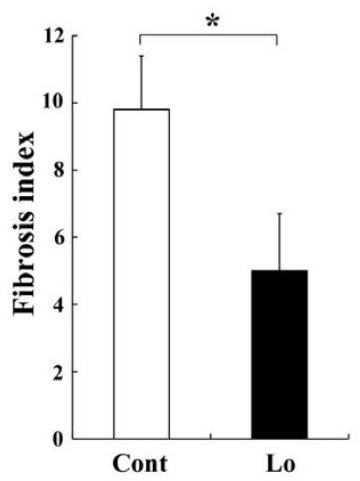

Figure I

Effect of losartan on the liver fibrosis development in the OLETF rats. (A): Microphotographs of the liver of CDAA-treated OLETF rats. (B): The fibrosis area was evaluated by an image-analyzer. Losartan ( $30 \mathrm{mg/kg/day)} \mathrm{signif-}$ icantly suppressed the CDAA-induced liver fibrosis development in the OLETF rats. Noteworthy was the finding that this inhibitory effect was achieved even at a clinically comparable low dose. The data represent the mean \pm SD (n $=5)$. *: Statistically significance between the indicated group $(\mathrm{p}<0.0 \mathrm{I})$.

CDAA-induced liver injury. Neither another several serum markers such as total cholesterol and total bilirubin were affected by losartan (Table 1). We next carried out the immunohistochemical analysis of $\alpha$-SMA to examine the effect of losartan on hepatic stellate cells (HSC) activation during liver fibrosis development. The inhibitory effect of losartan on $\alpha$-SMA exerted most parallel reduction (Fig. 2 ). The serum level of TGF-beta, that was mainly produced in the activated HSC, also suppressed by treatment of losartan at similar magnitude either (Table 1). These results suggested that the anti-fibrotic effect of losartan was achieved by suppression of HSC activation. AzanMallory staining was employed for determination of the liver fibrosis development, and the semi-quantitative analysis of fibrosis development and immunopositive cell area were carried out with a Fiji-BAS 2000 image analyzing system (Fuji, Tokyo, Japan) as described previously [8].

Noteworthy was the finding that this inhibitory effect was achieved even at a clinically comparable low dose. Since losartan is widely used in the clinical practice without serious side effects, this agent may be an alternative therapeutic agent against NASH. Actually, a pilot study has shown that ARB may exert beneficial effects in the patients with NASH [10]. A large-scale prospective randomized clinical trial is required in the future. 
A

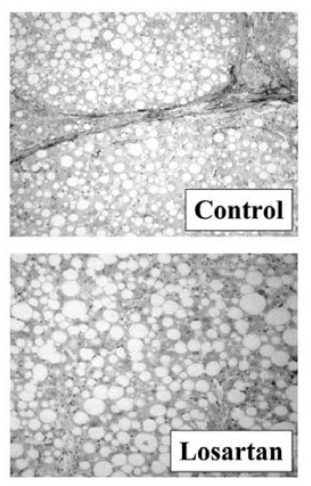

B

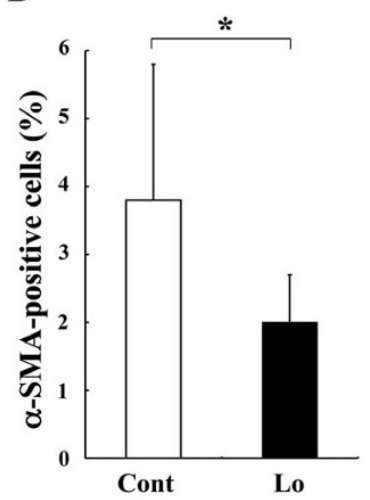

Figure 2

Effect of losartan $(30 \mathrm{mg} / \mathrm{kg} /$ day $)$ on the activated hepatic stellate cells in the OLETF rats. $(A)$ : Representative features of $\alpha$-SMA-positive activated hepatic stellate cells in the liver of CDAA-treated OLETF rats. (B): Densitometric analysis of $\alpha$-SMA-positive cells. The $\alpha$-SMA-positive cells were significantly suppressed by treatment with losartan almost in parallel with reduction of liver fibrosis development. The data represent the mean $\pm S D(n=5)$. *: Statistically significance between the indicated group $(p<0.0 I)$.

\section{Competing interests}

The authors declare that they have no competing interests.

\section{Authors' contributions}

HY conceived of the study, carried out the main body of the project and prepared the manuscript. RN, YI, TN, MK, KK, YS, JY, KY, MY, TT, HK, TK, YA, and HF participated the most part of the studies such as animal handling and

Table I: Effect of Losartan on several markers of the OLETF rats

\begin{tabular}{lll}
\hline & OLETF & OLETF+Losartan \\
\hline Body weight $(\mathrm{g})$ & $67 \mathrm{l} .3 \pm 35.2$ & $662 \pm 4 \mathrm{I} . \mathrm{I}$ \\
\hline Liver weight $(\mathrm{g})$ & $25.8 \pm 4.3$ & $22.4 \pm 4.0$ \\
\hline Glucose (mg/dl) & $27 \mathrm{l} .3 \pm 41.0$ & $262.0 \pm 36.8$ \\
\hline Insulin (nM/ml) & $128.0 \pm 10.4$ & $117.2 \pm 9.6$ \\
\hline ALT (IU/I/dl) & $102.4 \pm 17.8$ & $96.7 \pm 16.6$ \\
\hline Total bilirubin (mg/dl) & $0.11 \pm 0.07$ & $0.14 \pm 0.08$ \\
\hline Total cholesterol (nmol/l) & $1.04 \pm 0.12$ & $0.93 \pm 0.11$ \\
\hline TGF- $\beta$ (ng/mg liver) & $56.6 \pm 14.3$ & $34.3 \pm 10.1^{*}$ \\
\hline
\end{tabular}

Results are expressed as means \pm SD

*: Statistically significant diferences as compared with OLETF-control group

sample analysis. All authors read and approved the final manuscript.

\section{Acknowledgements}

Banyu Pharmaceutical Co., Ltd (Tokyo, Japan) generously supplied the losartan.

\section{References}

I. Reid AE: Nonalcoholic steatohepatitis. Gastroenterology 200I, I 2 I(3):7| 0-723.

2. Marrero JA, Fontana RJ, Su GL, Conjeevaram HS, Emick DM, Lok AS NAFLD may be a common underlying liver disease in patients with hepatocellular carcinoma in the United States. Hepatology 2002, 36(6): I349-I 354.

3. Vuppalanchi R, Chalasani N: Nonalcoholic fatty liver disease and nonalcoholic steatohepatitis: Selected practical issues in their evaluation and management. Hepatology 2009, 49(I):306-317.

4. Ratziu V, Giral P, Jacqueminet $S$, Charlotte F, Hartemann-Heurtier A, Serfaty L, Podevin P, Lacorte JM, Bernhardt C, Bruckert E, et al.: Rosiglitazone for nonalcoholic steatohepatitis: one-year results of the randomized placebo-controlled Fatty Liver Improvement with Rosiglitazone Therapy (FLIRT) Trial. Gastroenterology 2008, I35(I): 100-1 I0.

5. Liu Z: The renin-angiotensin system and insulin resistance. Current diabetes reports 2007, 7(I):34-42.

6. Yoshiji $\mathrm{H}$, Kuriyama S, Fukui $\mathrm{H}$ : Blockade of renin-angiotensin system in antifibrotic therapy. J Gastroenterol Hepatol 2007, 22(Suppl I):S93-95.

7. Hirose A, Ono M, Saibara T, Nozaki Y, Masuda K, Yoshioka A, Takahashi M, Akisawa N, Iwasaki S, Oben JA, et al: Angiotensin II type I receptor blocker inhibits fibrosis in rat nonalcoholic steatohepatitis. Hepatology 2007, 45(6): |375-|38|.

8. Yoshiji H, Yoshii J, Ikenaka Y, Noguchi R, Tsujinoue H, Nakatani T, Imazu H, Yanase K, Kuriyama S, Fukui H: Inhibition of renin-angiotensin system attenuates liver enzyme-altered preneoplastic lesions and fibrosis development in rats. J Hepatol 2002, 37(I):22-30.

9. Remuzzi A, Perico N, Amuchastegui CS, Malanchini B, Mazerska M, Battaglia C, Bertani T, Remuzzi G: Short- and long-term effect of angiotensin II receptor blockade in rats with experimental diabetes. J Am Soc Nephrol 1993, 4(I):40-49.

10. Yokohama S, Yoneda M, Haneda M, Okamoto S, Okada M, Aso K, Hasegawa T, Tokusashi Y, Miyokawa N, Nakamura K: Therapeutic efficacy of an angiotensin II receptor antagonist in patients with nonalcoholic steatohepatitis. Hepatology 2004, 40(5): $1222-1225$
Publish with BioMed Central and every scientist can read your work free of charge

"BioMed Central will be the most significant development for disseminating the results of biomedical research in our lifetime. "

Sir Paul Nurse, Cancer Research UK

Your research papers will be:

- available free of charge to the entire biomedical community

- peer reviewed and published immediately upon acceptance

- cited in PubMed and archived on PubMed Central

- yours - you keep the copyright

Submit your manuscript here:

http://www.biomedcentral.com/info/publishing_adv.asp
BioMedcentral 